\title{
Preload-Adjusted 2 Wave-Intensity Peaks Reflect Simultaneous Assessment of Left Ventricular Contractility and Relaxation
}

\author{
Masaru Nakayama, MD; Haruki Itoh, MD; Keiko Oikawa, MD; Akihiko Tajima, BS; \\ Akira Koike, MD; Tadanori Aizawa, MD; Long-tai Fu, MD; Fumihiko Miyake, MD*
}

\begin{abstract}
Background The magnitudes of the first (WI1) and the second wave-intensity peak (WI2) during the ejection period can be used as indices of left ventricular (LV) contractility and relaxation, respectively. However, use of WI to characterize LV dp/dt and the end-diastolic volume (Ved) relationship may be more problematic, as WI may be affected by changes in preload.

Methods and Results The LV pressure-volume data sets, consisting of 23 recordings obtained by the conductance method from 12 heart disease patients, were studied. End-systolic elastance (Ees) and volume-axisintercept $\left(\mathrm{V}_{0}\right)$ were calculated with varying preload. Time constant of LV relaxation $(\tau)$, Ved, and WI were calculated from steady-state averaged data. The Ees showed a weak correlation with $\mathrm{WI}_{1}(\mathrm{r}=0.46, \mathrm{p}<0.05)$ but a better correlation with preload-adjusted WI $\left[\mathrm{WI}_{1} / \mathrm{V}_{\text {ed }} ; \mathrm{r}=0.86, \mathrm{WI}_{1} / \mathrm{Ved}^{2} ; \mathrm{r}=0.92, \mathrm{WI}_{1} /\left(\mathrm{V}_{\text {ed }}-\mathrm{V}_{0}\right)^{2} ; \mathrm{r}=0.89\right.$, all $\mathrm{p}<0.01$ ]. Similarly, T did not correlate with WI2 but did correlate with preload-adjusted $\mathrm{WI}_{2}\left[\mathrm{WI} 2 / \mathrm{Ved} ; \mathrm{r}=-0.73, \mathrm{WI}_{2} / \mathrm{V}_{\text {ed }}{ }^{2}\right.$; $\mathrm{r}=-0.63, \mathrm{WI}_{2} /\left(\mathrm{V}_{\text {ed }}-\mathrm{V}_{0}\right)^{2} ; \mathrm{r}=-0.78$, all $\left.\mathrm{p}<0.01\right]$.

Conclusions These data demonstrate the importance of preload-adjustment when using the WI index for simultaneous assessment of LV contractility and relaxation. (Circ J 2005; 69: 683-687)
\end{abstract}

Key Words: Cardiac volume (preload dependence); Heart failure; Pressure volume relation; Ventricular function; Wave intensity

W ave-intensity (WI) is a hemodynamic index defined as the product of the incremental differences in pressure and velocity at any site in the circulation. Wave-intensity demonstrates 2 positive peaks during the ejection period, and the magnitudes of the first (WI1) and second peaks (WI2) can be used for the simultaneous noninvasive assessment of the left ventricular (LV) chamber contractility and relaxation performance, respectively!-6 However, the effect of varying degrees of LV volumes (ie, preload) on the use of this parameter has not been characterized6

Indeed, when considering maximum values of the derivative of LV pressure (LV dp/dt max) and the LV end-diastolic volume (Ved) relationship? or the elastance and the volumedependent flow changes in the end-ejection period, ${ }^{8-11} \mathrm{WI}_{1}$ may vary with preload. The goal of the present study was to determine whether the use of WI for the analysis of the pressure-volume relationship should be corrected for changes in preload. Theoretically, the end-systolic pressure-volume relationship by itself is an index of load dependent and of nonlinear characteristic, ${ }^{12}$ but is also relatively load independent in the physiological range of animals and humans! ${ }^{13-16}$ Therefore, the end-systolic pressure-volume relationship was used as a gold standard of the LV contractility.

(Received July 30, 2004; revised manuscript received March 4, 2005; accepted March 14, 2005)

The Cardiovascular Institute, Tokyo, *The Division of Cardiology, Department of Internal Medicine, St Marianna University School of Medicine, Kawasaki, Japan

Mailing address: Masaru Nakayama, MD, 7-3-10 Roppongi, Minatoku, The Cardiovascular Institute, Tokyo 106-0032, Japan. E-mail: ms-nakayama@kashima.jp

\section{Methods}

Patients

Twenty-three invasive LV pressure-volume data sets were selected from a population of patients that had undergone an invasive pressure-volume catheterization study at the Cardiovascular Institute Hospital within the past several years. Selection was based purely on an adequate signal/noise ratio for the volume measurement before and during preload reduction maneuvers. The study subjects included 12 patients. Of these, 7 subjects underwent subsequent studies to evaluate the effects of interventions (eg, additional medications, LV volume reduction surgery, cardiac resynchronization therapy, pericardiectomy surgery). Thus, the study data consisted of 23 pressure-volume measurement recordings, including 15 data sets from 6 patients with dilated cardiomyopathy [ 6 baseline data sets; 7 data sets of additional medication therapies, including angiotensin convedrting enzyme-inhibitors and/or carvedilol; 1 data set obtained after LV volume reduction surgery; 1 data set obtained after cardiac resynchronization therapy; 3 data sets from 3 patients with coronary artery disease (including 1 patient with an old myocardial infarction); 3 data sets from 1 patient with constrictive pericarditis (baseline, after medication, and after pericardiectomy surgery); and 2 data sets from 2 patients with anginal symptoms but normal cardiac function (Table 1)]. The Ethical Committee on Clinical Investigation of the Cardiovascular Institute approved the protocol, and written informed consent was obtained from all patients.

\section{Procedure}

Details of the pressure-volume catheterization procedure 
Table 1 Baseline Characteristics of the Study Subjects

\begin{tabular}{lr}
\hline \hline Variables & \\
\hline Age $($ years; mean $\pm S D)$ & $55 \pm 9$ \\
Sex $($ male) & 12 \\
Referred for cardiac catheterization [n (data points)] & \\
Dilated cardiomyopathy & $6(15)$ \\
Coronary artery disease & $3(3)$ \\
Vasospastic angina & $2(2)$ \\
Constrictive pericarditis & $1(3)$ \\
Measured parameters [mean $\pm S D($ range $)]$ & \\
Ved $(\mathrm{ml})$ & $271 \pm 160(67-601)$ \\
Ves $(\mathrm{ml})$ & $182 \pm 147(18-522)$ \\
LVEF $(\%)$ & $42 \pm 19(13-73)$ \\
SBP $(\mathrm{mmHg})$ & $102 \pm 15(82-151)$ \\
EDP $(\mathrm{mmHg})$ & $21 \pm 7(12-37)$ \\
Ees $(\mathrm{mmHg} / \mathrm{ml})$ & $1.18 \pm 0.67(0.42-2.61)$ \\
Vo $(\mathrm{ml})$ & $71 \pm 106(-44-239)$ \\
$\mathrm{T}(\mathrm{ms})$ & $55.6 \pm 11.4(40-77)$ \\
$W I \mathrm{H}\left(\mathrm{mmHg} \cdot \mathrm{ml} \cdot \mathrm{s}^{-3}\right)$ & $11,696 \pm 8,437(1,080-25,680)$ \\
$W I 2\left(\mathrm{mmHg} \cdot \mathrm{ml} \cdot \mathrm{s}^{-3}\right)$ & $7,861 \pm 5,015(1,287-20,910)$ \\
\hline
\end{tabular}

Ved, left ventricular end-diastolic volume; Ves, left ventricular end-systolic volume; LVEF, left ventricular ejection fraction; SBP, systolic blood pressure; EDP, end-diastolic pressure; Ees, end-systolic elastance; $V$ o, volume axis intercept; $\mathrm{T}$, time constant of left ventricular relaxation; WII, first wave-intensity peak; WI2, second wave-intensity peak. Values are mean $\pm S D$ or number of patients.

and analysis have been previously described and validated!7,18 Briefly, all patients underwent routine right- and left-heart catheterization, coronary arteriography, and left ventriculography, and pressure-volume were recorded under resting conditions and during brief rapid changes in ventricular filling induced by transient obstruction of inferior vena cava inflow with a balloon catheter (SP: 9168, Cordis, USA) or by the abdominal compression method to impede venous return for approximately 10 s (the LV end-diastolic volumes were reduced by approximately $35 \%$ in all of these procedures; data not presented). A stimulator/processor unit (Sigma-5, CardioDynamics, The Netherlands) was used for LV volume measurements. LV pressure was assessed using a micromanometer catheter (SPC-320, Millar Inc, USA) placed within the lumen of the volume catheter (Conductance Catheter, Alpha Medical Instruments, USA). Adding signals from the volume catheter yield a continuous time-varying waveform proportional to cavity volume. The catheter volume signal was calibrated by matching ventriculography-derived end-diastolic and end-systolic volumes. Hemodynamic signals were digitized at $1,000 \mathrm{~Hz}$ with custom data acquisition display software (Physio-Tech, Tokyo, Japan) and were analyzed offline.

\section{Analysis}

The original concept of wave intensity was defined as $\mathrm{dp} \cdot \mathrm{dU}$ or as the instantaneous product of the changes in pressure (p) and velocity (U) ${ }^{1-4}$ However, this original wave intensity depends on the data-sampling interval, making comparisons at different sampling rates problematic. The time-normalized wave intensity, which is defined as $(\mathrm{dp} / \mathrm{dt}) \cdot(\mathrm{dU} / \mathrm{dt})$, has also been used ${ }^{1-3}$ Thus, the averaged data of 5 to 8 pressure-volume loops under a steadystate condition was used to calculate the time-normalized WI. This was derived after smoothing the conductance catheter-derived volume-waveform [V(t)] with a 4-term Fourier filter, for which an analytical derivative was obtained. During the ejection period, the conductance catheter-derived rate of volume change $(-\mathrm{dV} / \mathrm{dt}=$ flow $)$ can closely resemble velocity, assuming the LV outflow

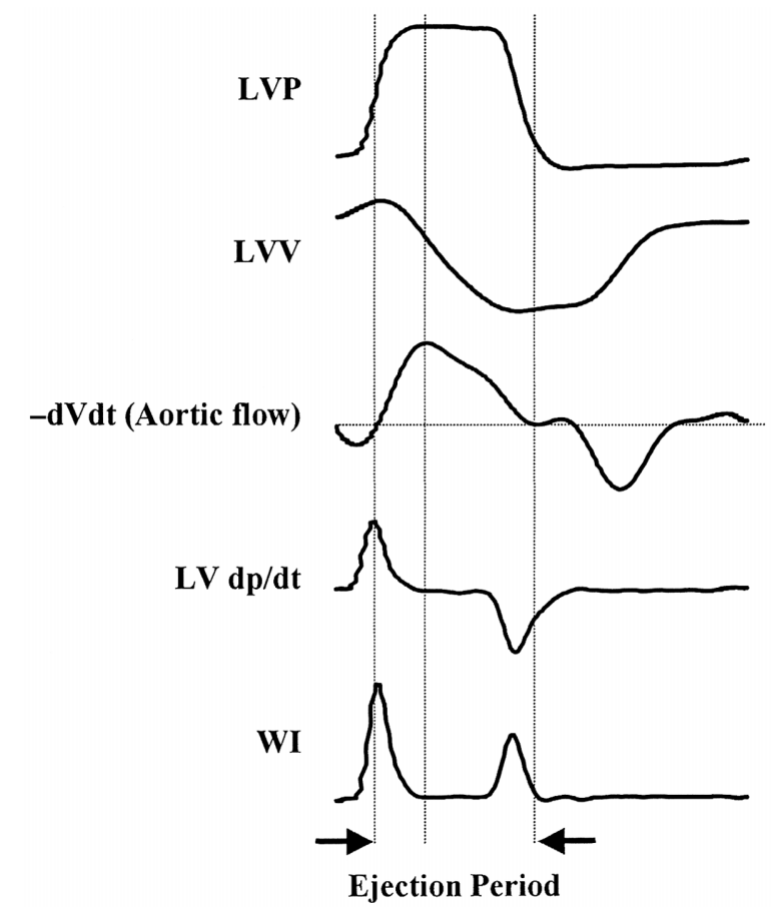

Fig 1. Representative simultaneous recordings of left ventricular pressure (LVP) waveform, left ventricular volume (LVV) waveform, and computed aortic flow $(-\mathrm{dV} / \mathrm{dt})$, derivative of left ventricular pressure (LV dp/dt), and wave-intensity (WI) from the pressure-volume loop data.

remains constant. This is represented by:

$\mathrm{WIA}=(\mathrm{dp} / \mathrm{dt}) \cdot(\mathrm{dU} / \mathrm{dt})=(\mathrm{dp} / \mathrm{dt}) \cdot\left[(-\mathrm{dV} / \mathrm{dt}) /(\mathrm{dt}) \cdot \pi \cdot(\mathrm{D} / 2)^{2}\right]$

$\mathrm{dp} / \mathrm{dt}$; incremental differences in LV pressure

$\mathrm{dU} / \mathrm{dt}$; incremental differences in $\mathrm{LV}$ velocity

$-\mathrm{dV} / \mathrm{dt}$; rate of LV volume change (=flow)

$\mathrm{D}$; distance of LV out-flow tract

$\mathrm{WI}_{1}$ and $\mathrm{WI}_{2}$ were defined as the magnitudes of the first peak and second peak of the WI during ejection period (Fig 1).

Ved, end-systolic volume, LV ejection fraction, systolic blood pressure, end-diastolic pressure, and the time constant of LV relaxation ( $T$ ) were also determined from the averaged data.T was calculated by the derivative method 11 End-systolic elastance (Ees) was defined as the linear slope of the end-systolic pressure-volume relation,,8 and the volume axis was represented by the intercept of this relationship ( $\left.\mathrm{V}_{0}\right)$.

A preload-adjustment method [ $\mathrm{V}_{\text {ed }}, \mathrm{V}_{\text {ed }}{ }^{2}$, and $\left.\left(\mathrm{V}_{\text {ed }}-\mathrm{V}_{0}\right)^{2}\right]$ was used to examine the preload dependence of WI 1 and $\mathrm{WI} 2{ }^{19,20}$

\section{Statistical Analysis}

Data are presented as mean \pm SD. Relationships between 2 parameters were analyzed by the least-squares linear regression method. Multivariate estimates of the regressions with Ees (or T ) were calculated by general linear models adjusted for WI1 families (or WI2 families). Statistical significance was designated at $\mathrm{p}<0.05$.

\section{Results}

The baseline characteristics of the study subjects are summarized in Table 1. Patients reflected a broad range of 
A

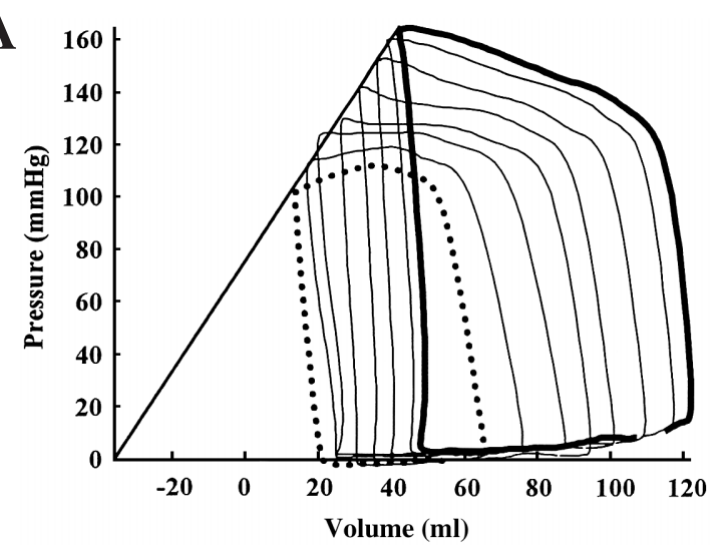

C $\left(\mathbf{x 1 0}^{4}\right)$

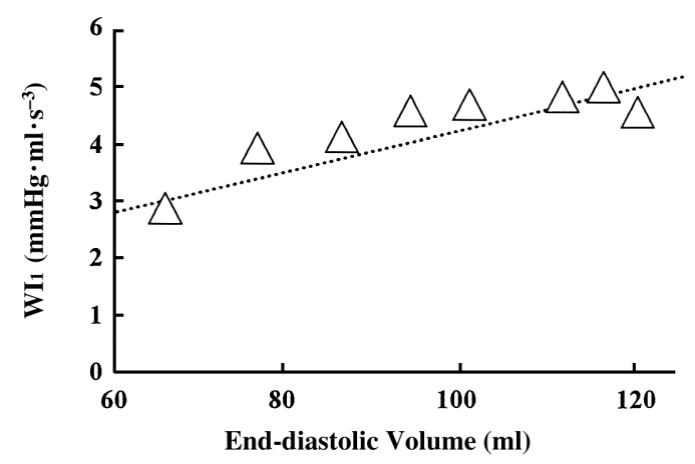

B

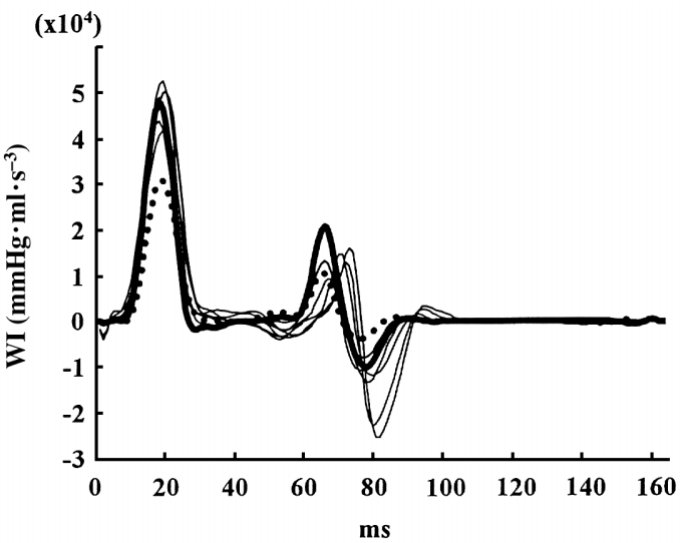

D

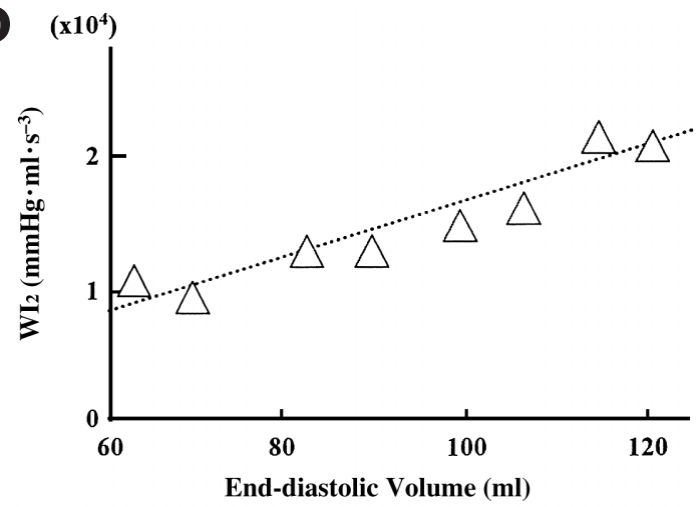

Fig 2. (A) An example of pressure-volume loops at varying preloads. End-systolic pressure-volume relationship (Ees) appeared to have a negative volume-axis-intercept $\left(\mathrm{V}_{0}\right)$. Bold solid curve indicates pressure-volume loop at the steadystate, and bold dashed curve indicates pressure-volume loop at the maximum preload reduction. (B) Wave-intensity (WI) calculated for each beat is traced. WI has 2 positive shape peaks during ejection period, and the magnitudes of its first peak (WI1) and second peak (WI2) are reduced by preload reduction. Bold solid and dashed lines are linked with Fig 2A. (C) WI 1 calculated for each beat is plotted vs end-diastolic volume ( $\mathrm{V}_{\text {ed }}$ ). (D) WI2 calculated for each beat is plotted vs Ved. WI1 and WI2 decrease in accordance with the reduction of Ved.
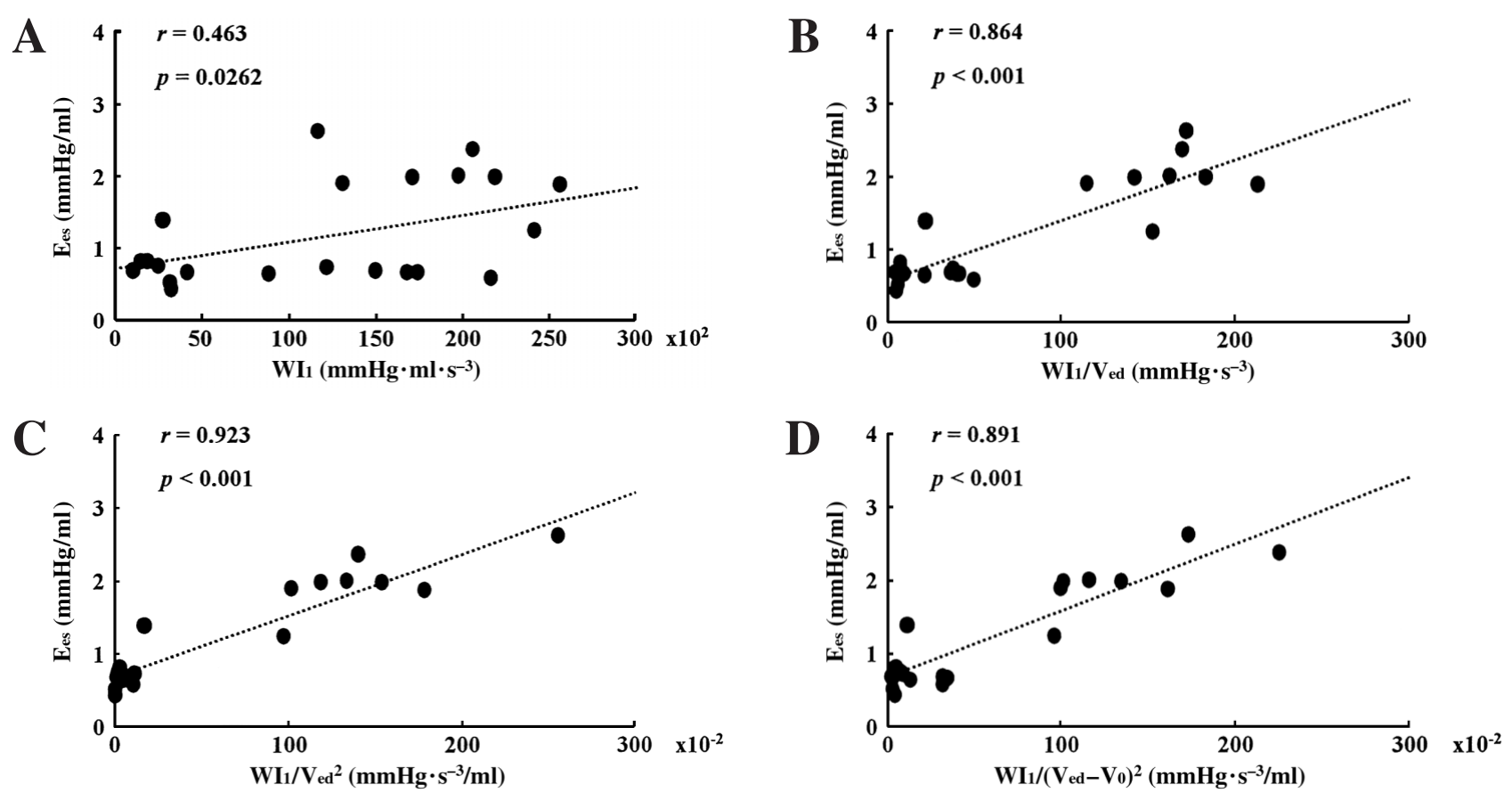

Fig 3. (A) Relationship between the end-systolic elastance (Ees) and WI1. Significant positive correlation is observed, but data are scattered. (B-D) Relationships between Ees and the 3 preload-adjustment methods of WI1. Significant positive correlations are observed. 
A

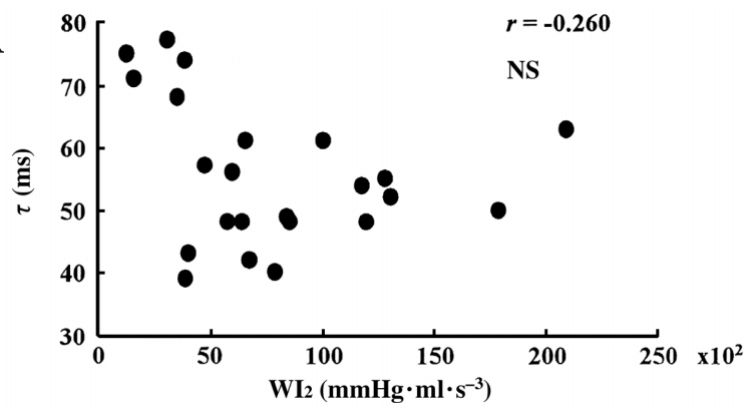

C

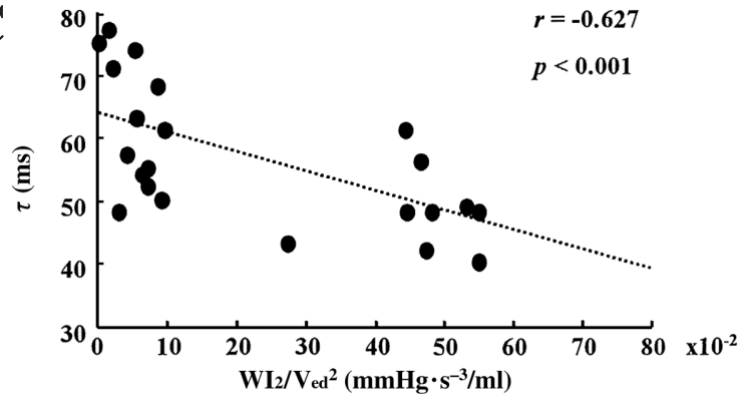

B

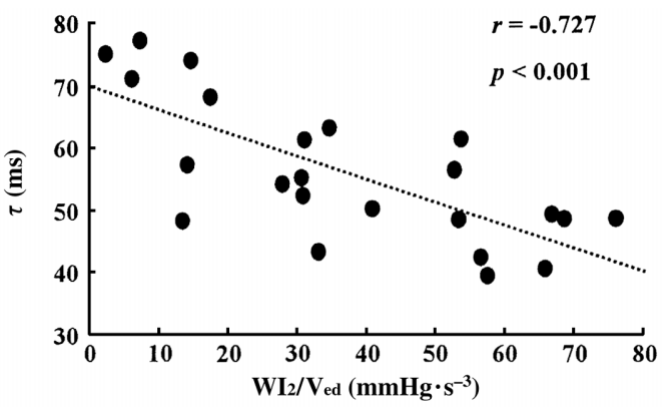

D

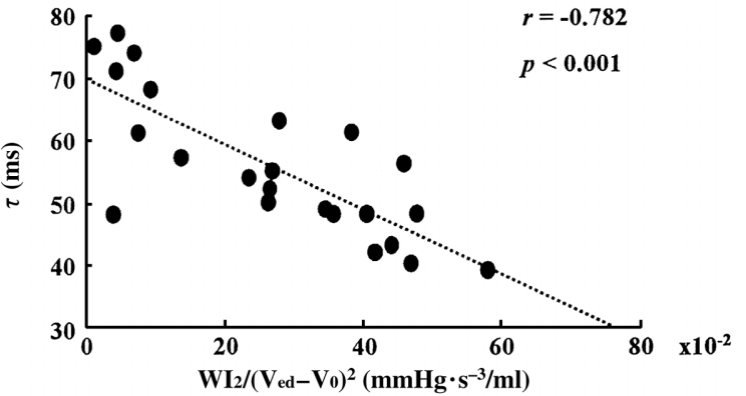

Fig 4. (A) Relationship between the time constant of left ventricular relaxation ( $\mathrm{T}$ ) and WI2. There is no significant correlation. (B-D) Relationships betweent and the 3 types of preload-adjustment methods of WI2. Significant negative correlations are observed.

Table 2 Relationship Between Ees, and WI1 Families

\begin{tabular}{lcrc}
\hline \hline & $\begin{array}{c}\text { Estimaetd regression of } \\
\text { coefficient with Ees }\end{array}$ & t value & $p$ value \\
\hline$W I_{1}$ & -0.485 & -2.796 & 0.0119 \\
$W I_{I} / V_{\text {ed }}$ & 0.676 & 1.603 & 0.1265 \\
$W I_{1} /$ Ved $^{2}$ & 0.169 & 0.534 & 0.6001 \\
$W I /\left(V_{\text {ed }}-V_{o}\right)^{2}$ & 0.439 & 1.897 & 0.0739 \\
\hline
\end{tabular}

Total-adjusted $R^{2}=0.908, p<0.0001$.

LV chamber size, contractility, and relaxation performance. Analysis of the pressure-volume data revealed that WI 1 and WI2 decreased in accordance with the reduction of $V_{\text {ed }}$ (Fig 2). WI1 was weakly correlated with Ees $(\mathrm{r}=0.463$, $\mathrm{p}=0.0262$; Fig $3 \mathrm{~A}$ ), while preload-adjusted WI1 showed a relatively strong correlation with Ees $[(\mathrm{Fig} 3 \mathrm{~B}) \mathrm{WI} / \mathrm{Ved}$; $\mathrm{r}=0.864$, (Fig 3C) WI $/ \mathrm{Ved}^{2} ; \mathrm{r}=0.923$, (Fig 3D) WI $1 /\left(\mathrm{Ved}_{\text {ed }}\right.$ $\left.\mathrm{V}_{0}\right)^{2} ; \mathrm{r}=0.891$, all $\left.\mathrm{p}<0.001\right]$. In contrast to previous reports, WI2 did not correlate with T (Fig 4A). However, preloadadjusted $\mathrm{WI}_{2}$ did correlate with $\mathrm{T}$ [(Fig 4B) $\mathrm{WI}_{2} / \mathrm{Ved}_{\text {ed }}$ r= -0.727 , (Fig 4C) $\mathrm{WI}_{2} / \mathrm{Ved}^{2} ; \mathrm{r}=-0.627$, (Fig 4D) $\mathrm{WI}_{2} /(\mathrm{Ved}-$ $\left.\mathrm{V}_{0}\right)^{2} ; \mathrm{r}=-0.782$, all $\left.\mathrm{p}<0.001\right]$.

Data describing the influences of the preload-adjustment methods of WI1 on Ees, and of WI2 ont are summarized in Tables 2 and 3. An alternative formulation of the preloadadjustment method as $\mathrm{WI}_{1} / \mathrm{Ved}^{2}$ yielded a better correlation with Ees, and $\mathrm{WI}_{2} /\left(\mathrm{V}_{\mathrm{ed}}-\mathrm{V}_{0}\right)^{2}$ incorporating $\mathrm{V}_{0}$ yielded a better correlation with $\mathrm{T}$. These data demonstrate the importance of preload adjustment when using the WI index for simultaneous assessment of LV contractility and early filling dynamics.

\section{Discussion}

Previous studies have demonstrated that the magnitude of the first WI peak corresponded to LV contractile function, while the amplitude of the second WI peak corre-
Table 3 Relationship Betweent, and WI2 Families

\begin{tabular}{lccc}
\hline \hline & $\begin{array}{c}\text { Estimaetd regression of } \\
\text { coefficient with } \mathrm{T}\end{array}$ & t value & p value \\
\hline$W I_{2}$ & -0.092 & -0.331 & 0.7445 \\
$W I_{2} / V_{\text {ed }}$ & -0.102 & -0.198 & 0.8453 \\
$W I_{2} /$ ed $^{2}$ & -0.062 & -0.105 & 0.9175 \\
$W I_{2} /\left(\text { Ved }_{\text {edo }}\right)^{2}$ & -0.618 & -1.682 & 0.1099 \\
\hline
\end{tabular}

Total-adjusted $R^{2}=0.623, p=0.0010$.

sponded to the inertial force of late systolic aortic flow and to the speed of LV relaxation? Therefore, based on theoretical considerations, the magnitude of the first WI peak correlates with dp/dtmax. However, on the basis of the LV

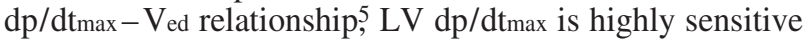
to changes in preload change. This is the first study to provide direct evidence that magnitude of the first WI peak is dependent on preload. Preload-adjusted 2 WI peaks during the ejection period can assess the LV chamber contractility and relaxation performance simultaneously and noninvasively6 These techniques may have use in the diagnosis of heart failure, including heart failure due to diastolic dysfunction 19 However, determination of the optimal preloadadjustment method is required before this technique can be applied clinically.

A variety of clinical studies have demonstrated the use of maximal LV power (PWRmax) indices for the noninvasive assessment of chamber contractility and contractile reserve ${ }^{20-22}$ PWR max is the peak instantaneous product of chamber pressure and rate of volume change that varies with changes in preload but not with changes in afterload. While the preload-adjusted PWRmax is usually calculated with PWRmax $/ V_{\text {ed }}$ or PWRmax $/ \mathrm{Ved}^{2}$, the optimal method for preload-adjustment remains unclear21 One formulation of the preload-adjusted PWR max as PWR $\max /\left(\mathrm{V}_{\text {ed }}-\mathrm{V}_{0}\right)^{2}$, incorporating $\mathrm{V}_{0}$, has been validated in an animal model $2^{23}$ As PWRmax, and WI are based on similar properties (eg, pres- 
sure and flow/velocity), WI would also be expected to vary with preload. Indeed, Ees showed a stronger correlation with preload-adjusted $\mathrm{WI}_{1}$, which underscores the importance of preload adjustments when using the WI 1 index for assessment of LV contractility.

The pathophysiologic significance of the second WI peak remains unclear 24,25 During the period of the second WI peak, forward waves are predominant $(\mathrm{WI}>0)$, which suggests that the left ventricle may actively interfere with forward aortic blood flow. For example, Sugawara et al ${ }^{26}$ reported that the inertia of the aortic flow near end-ejection enhances LV relaxation, which subsequently results in the termination of forward aortic blood flow. In contrast, isometric tension is maintained during late systole, despite the inability of the LV muscle to shorten any further. Thus, the inertia of the blood flowing out of the left ventricle causes rapid end-systolic unloading and produces a much smaller LV end-systolic volume and much greater elastic recoil. Thus, the inertial force contributes to the deceleration of aortic flow and results in a much greater WI. Accordingly, the magnitude of the second WI peak should correlate with LV relaxation performance. While a previous study demonstrated a relationship between the second WI peak andT 6 , the present study demonstrated that correlated with preload-adjusted WI2.

In theory, all ejection phase indices should be sensitive to preload and afterload. During the ejection period, pressure changes occur secondary to the elastance and the volumedependent flow/velocity generation changes, which suggests that the second peak of WI should be sensitive to changes in the preload as well.-11 Indeed, the present study demonstrated a stronger correlation betweent and preloadadjusted $\mathrm{WI} 2$.

\section{Study Limitations}

The present study was unable to test the reliability of the velocity data derived from the conductance method. In theory, WI must be calculated from LV pressure, and velocity should be measured at the same cross-section of flow. Although we assumed that the cross-section of LV outflow is constant during the ejection period, Courtois et al and others have shown that there are substantial pressure gradients within the LV during diastolic filling. ${ }^{27}$ Although the diameter of the cross-section of LV outflow may change during ejection, the differences were likely to be extremely small and within the physiological range. This supposition is consistent with observations from animal studies and from theoretic models of PWRmax analysis. ${ }^{20-23}$ Thus, while useful information may be obtained from velocity data derived from pressure-volume analysis, investigators should be aware of these limitations.

\section{Conclusions}

The current study demonstrated the importance of preload adjustment when using the WI index for simultaneous assessment of LV contractility and relaxation.

\section{References}

1. Ramsey MW, Sugawara M. Arterial wave intensity and ventriculoarterial interaction. Heart Vessels 1997; 12(Suppl): 128-134.

2. Niki K, Sugawara M, Uchida K, Tanaka R, Tanimoto K, Imamura H, et al. A noninvasive method of measuring wave intensity, a new hemodynamic index: Application to carotid artery in patients with mitral regurgitation before and after surgery. Heart Vessels 1999; 14:
$263-271$

3. Jones CJH, Sugawara M, Kondoh Y, Uchida K, Parker KH. Compression and expansion wavefront travel in canine ascending aortic flow: Wave intensity analysis. Heart Vessels 2002; 16: 91-98.

4. Fujimoto S, Oki T, Tabata T, Tanaka H, Yamada H, Oishi Y, et al. Novel approach to the quantitation of regional left ventricular systolic and diastolic function using tissue Doppler imaging to create a myocardial velocity profile and gradient. Circ J 2003; 67: 416-422.

5. Zhang H, Otuji Y, Matsukida K, Hamasaki S, Yoshifuku S, Kumanohoso T, et al. Noninvasive differentiation of normal from pseudonormal/restrictive mitral flow using TEI index combining systolic and diastolic function. Circ J 2002; 66: 831 -836.

6. Ohte N, Narita H, Sugawara M, Niki K, Okada T, Harada A, et al. Clinical usefulness of carotid arterial wave intensity in assessing left ventricular systolic and early diastolic performance. Heart Vessels 2003; 18: $107-111$.

7. Little WC. The left ventricular $\mathrm{dP} / \mathrm{dt} \max$-end-diastolic volume relation in closed chest dogs. Circ Res 1985; 56: 808-815.

8. MacRae JM, Sun YH, Isaac DL, Dobson GM, Cheng CP, Little WC, et al. Wave-intensity analysis: A new approach of left ventricular filling dynamics. Heart Vessels 1997; 12: 53-59.

9. Santamore WP, Constantinescu M, Vinten-Johansen J, Johnston WE, Little WC. Alternations in left ventricular compliance due to changes in right ventricular volume, pressure and compliance. Cardiovasc Res 1988; 22: 768-776.

10. Little WC, Downes TR, Applegate RJ. Invasive evaluation of left ventricular diastolic performance. Herz 1990; 15: 362-376.

11. Belenkie I, Smith ER, Tyberg JV. Ventricular interaction: From bench to bedside. Ann Med 2001; 33: 236-241.

12. Su JB, Crozatier B. Preload-induced curvilinearity of left ventricular end-systolic pressure-volume relations: Effects on derived indexes in closed-chest dogs. Circulation 1989; 79: 431 - 440.

13. Sodoms MT, Badke FR, Starling MR, Little WC, O'Rourke RA. Evaluation of left ventricular contractile performance utilizing endsystolic pressure-volume relationships in conscious dogs. Circ Res 1984; 54: 731-739.

14. Kass DA, Maughan WL. From "Emax" to pressure-volume relations: A broader view. Circulation 1988; 77: 1203-1212.

15. Feldman MD, Park PH, Wu CC, Haber HL, Heesch CM, Bergin JD, et al. Acute cardiovascular effects of OPC-18790 in patients with congestive heart failure. Circulation 1996; 93: 474-483.

16. Kameyama T, Asanoi H, Ishizuka S, Sasayama S. Ventricular load optimization by unloading therapy in patients with heart failure. $J$ Am Cardiol 1991; 17: 199-207.

17. Kass DA, Yamazaki T, Burkhoff D, Maughan WL, Sagawa K. Determination of left ventricular end-systolic pressure-volume relationship by the couductance (volume) catheter technique. Circulation 1986; 73: $589-595$.

18. Szwarc RS, Mickleborough LL, Mizuno S, Silson GJ, Liu P Mohamed S. Conductance catheter measurements of left ventricular volume in the intact dog: Parallel conductance is independent of left ventricular size. Cardiovasc Res 1994; 28: 252-258.

19. Chen CH, Nakayama M, Nevo E, Fetics BJ, Maughan WL, Kass DA. Coupled systolic-ventricular and vascular stiffening with age: Implications for pressure regulation and cardiac reserve in the elderly. J Am Coll Cardiol 1998; 32: 1221-1227.

20. Kass DA, Beyar R. Evaluation of contractile state by maximal ventricular power divided by the square of end-diastolic volume. Circulation 1991; 84: 1698-1708.

21. Nakayama M, Chen CH, Nevo E, Fetics B, Wong E, Kass DA. Optimal preload adjustment of maximal ventricular power index varies with cardiac chamber size. Am Heart J 1998; 136: 281-288.

22. Kass DA, Van Anden E, Becker LC, Kasper EK, White WB, Feldman AM. Dose dependence of chronic positive inotropic effect of vesnarinone in patients with congestive heart failure due to idiopathic or ischemic cardiomyopathy. Am J Cardiol 1996; 78: 652-656.

23. Segers P, Sato VT, Leather HA, Lambermon B, Ghuysen A, Dogne JM, et al. Determinants of left ventricular preload-adjusted maximal power. Am J Physiol Heart Circ Physiol 2003; 284: 2295-2301.

24. Parker KH, Jones CJH, Dawson JR, Gibson DG. What stops the flow of blood from the heart? Heart Vessels 1988; 16: 241-245.

25. Parker KH, Jones CJH. Forward and backward running waves in the arteries: Analysis using the method of characteristics. ASME $J$ Biomech Eng 1990; 113: 322 - 326.

26. Sugawara M, Uchida K, Kondoh Y, Magosaki N, Niki K, Jones CJH, et al. Aortic blood momentum-the more the better for the ejecting heart in vivo? Cardiovasc Res 1997; 33: 433-446.

27. Courtois M, Vered Z, Barzilai B, Ricciotti NA, Perez JE, Ludbrook PA. The transmitral pressure-flow velocity relation. Effect of abrupt preload reduction. Circulation 1988; 78: 1459-1468. 